\title{
Economic Convergence or Divergence in the EU?
}

The 8th annual Intereconomics/CEPS conference took place in Brussels on 9 October 2018. This issue features contributions from our conference participants who take a closer look at the trends and driving factors of convergence and divergence. They examine the ripples created by the 2008 financial crisis in different parts of the EU, the impact of institutions and policy measures, alternative approaches such as the 'convergence of opportunities for people and firms' as well as the specific regional factors at play. Our contributors offer a deeper insight into answers to the question: "Economic convergence or divergence in the EU?"

Economic Integration and Income Convergence in the EU

Cinzia Alcidi, Centre for European Policy Studies, Brussels, Belgium.

How Can Europe Upgrade Its "Convergence Machine"?

Cristobal Ridao-Cano, World Bank, Washington, DC, USA.

Christian Bodewig, World Bank, Brussels, Belgium.

Fifteen Years of Convergence: East-West Imbalance and What the EU Should Do About it László Andor, Corvinus University of Budapest, Hungary.

Unravelling the Roots of the EMU Crisis Structural Divides, Uneven Recoveries and Possible Ways Out

Giuseppe Celi, University of Foggia, Italy.

Dario Guarascio, National Institute for the Analysis of Public Policies (INAPP), Rome, Italy.

Annamaria Simonazzi, Sapienza University of Rome, Italy.

Convergence and Divergence in the EU: Lessons from Italy

Barry Eichengreen, University of California, Berkeley, USA.

Convergence of the German Bundesländer: Lessons for the EU

Michael C. Burda, Humboldt Universität zu Berlin, Germany.

Divergence? What Divergence?

Charles Wyplosz, Graduate Institute, Geneva, Switzerland; and Centre for Economic Policy Research, London, UK.

Incentivising Structural Reforms in Europe? A Blueprint for the European Commission's Reform Support Programme

Mathias Dolls, Ifo Institute, Munich, Germany.

Clemens Fuest, Ifo Institute, Munich, Germany.

Carla Krolage, Ifo Institute, Munich, Germany.

Florian Neumeier, Ifo Institute, Munich, Germany.

Daniel Stöhlker, Ifo Institute, Munich, Germany. 